\title{
Using Video to Record Summary Lectures to Aid Students' Revision
}

\author{
Janice Whatley and Amrey Ahmad \\ University of Salford, Manchester, UK
}

\section{J.E.Whatley@salford.ac.uk aamrey@salford.ac.uk}

\begin{abstract}
Video as a tool for teaching and learning in higher education is a multimedia application with considerable promise. Including video within the online support material for a module can help students to gain an understanding of the material and prepare for assessment. We have experimented with using short videos that summarise the lectures given, as an aid for students to use when revising. An interpretive method has been adopted to investigate the use students make of these videos, during the teaching term and when revising for assessment. In this paper a summary of ways that video can be used for supporting teaching and learning is given, the ways in which we used video are presented followed by discussion of some issues relating to producing summary length videos. Preliminary research indicates that students find these summary lectures very useful for reviewing lecture material as well as for their revision.
\end{abstract}

Keywords: Video, learning, revision, assessment.

\section{Introduction}

In Higher Education students are spending more time at their own PCs away from the university campus, particularly those studying computing related subjects. Students at the HE level are required to explore more about the subject they are studying as an adjunct to the basic information given by a lecturer, in this way becoming self-sufficient learners. This active learning style, and access to a variety of learning materials, is essential for students to succeed in their studies at university. In addition, pressures of working and constraints of travel mean that they no longer spend all day and every day on campus. Support for their learning is being provided in the form of Virtual Learning Environments (VLE), where tutors can upload various study related documents and files for students to use wherever and whenever they choose to study. One of the difficult learning activities to support with online provision is the tutor's lecture, because as an essentially realtime, interactive event it is difficult to recreate these elements online (Bligh, 1974).

In this paper we explore the use that can be made of video to enhance student learning, and describe an experiment we performed to provide short summary lectures online, as revision aids for

Material published as part of this publication, either on-line or in print, is copyrighted by the Informing Science Institute. Permission to make digital or paper copy of part or all of these works for personal or classroom use is granted without fee provided that the copies are not made or distributed for profit or commercial advantage AND that copies 1) bear this notice in full and 2) give the full citation on the first page. It is permissible to abstract these works so long as credit is given. To copy in all other cases or to republish or to post on a server or to redistribute to lists requires specific permission and payment of a fee. Contact Publisher@InformingScience.org to request redistribution permission. our students. We are investigating a technique whereby the lecturer prepares a 10 minute video composed of a summary of the key points from the lecture. This can be supported by textual information, such as the PowerPoint slides of the lecture or selected text from lecture handouts. The video is based on the "talking head" method, of showing the 
lecturer speaking, with audio of what is spoken.

\section{Some Learning Theory Supporting the Use of Video}

Traditionally, learning in Higher Education revolves around lectures, tutorials, practical work etc. In the domain of Information Technology or Information Systems, students are technically oriented, with the result that there is a greater expectation for using technology for supporting learning (Issroff \& Scanlon, 2002). Virtual learning environments, such as Blackboard, are used extensively, to provide repositories for learning materials, which may be enhanced by interactive discussion boards and chat systems. Phelps suggests that recent fast changes in technologies, such as hand held computers, the Internet and digital sound and imaging, have not been adopted by educationalists, despite the fact that the technologies such as video recording have become easier for non-technical people to use (Phelps \& Tidmarsh, 2005). Indeed Lizewski (2004) argues that the cultural environment of an organisation affects the rate of adoption of learning technology.

Research suggests that learning requires visual as well as auditory stimulus, particularly when technology is being used, in order to promote cognitive processing. Mayer describes some principles of learning which are relevant to designing multimedia for learning, including:

- multimedia principle - learning is improved using words and pictures in preference to words alone;

- contiguity principle - learning is improved when pictures and related words are presented at the same time or next to each other on the screen;

- modality principle - spoken words are better than printed text for explaining images;

- signaling principle - learning material should be organised with clear outlines and headings; and

- personalization principle - a conversational style is better than a formal style for learning (Mayer 2001).

Sorden (2005) suggests that using a framework based on this type of theory is essential for producing effective multimedia teaching material (Sorden, 2005).

"Images can be worth 1000 words", and moving images, as video, can add authenticity to the portrayal of theoretical material. Video can enable improved communication of lecture material. According to the "cue-summation" theory of learning, increasing the number of stimuli makes learning more effective (Severin, 1967). Using visual information as an additional channel can aid the retention of verbal information, according to Mayer and Anderson (Mayer \& Anderson, 1991).

The idea of the "sage on the stage" is still a predominant method of lecturing in higher education, because it is an efficient means of putting information over to a large audience. But what about the students who easily forget the lecturer's words? Or the students who travel long distances and so may arrive late, or are unable to attend the lecture for personal reasons? Is it possible to provide an archive facility for students to revisit a lecture at a later date? The next sections will outline current ways in which video is being used to support student learning, followed by examples.

\section{How Video can be Used}

As video recorders (camcorders) including webcams, become cheaper and simpler to use, it is possible for anyone with a little technical know how to produce a video, which can be distributed in a variety of ways, including on CD, DVD or online. Video is a combination of a moving image and accompanying sound, so whereas an audio recording gives the voice or sound alone, video retains the visual cues that are essential for full understanding of the communication. 
Video as an instructional tool and a communication medium has been widely used over last two decades in classroom and distance education. Shepard \& Cooper (1982) indicated that use of visual cues creates imagery during learning that is critical to memory processes. Video, as an educational media, can provide vivid descriptions to articulate tacit information and knowledge difficult to achieve through text or verbally (Goodyear \& Steeples, 1998).

There are several ways to use video in teaching, including "talking head" lectures (images of the lecturer's face and shoulders), interviews, video diaries, "fly on the wall" recording, demonstrations and instructions (Young \& Asensio, 2003). Broadband connection to the Internet enables us to distribute the recordings online for the benefit of students, providing for greater accessibility for all (Shephard, 2004). We are now looking for ways to use video in more imaginative ways, which are pedagogically sound, and help students to achieve learning outcomes, moving away from using video just as a presentation tool, to using it also as a tool for networked learning (Young \& Asensio, 2003).

From a learning perspective, students may benefit from the ability to watch again any lecture, to enrich their notes taken at the time, as an important step in learning the presented material. Students may be directed to watch a video before attending a workshop, so that material contained in it may be explored in depth (Vogel \& Oliver, 2006). Alternatively video may be used to demonstrate a practical skill, with the possibility that it can be played over and over again until the skill has been mastered.

\section{Full Length Video of Lectures}

A simple solution is to record an entire lecture, and make it available without editing the original footage. A guest speaker, who is an expert in the field, and who would not be able to travel to the higher education institution more than once to give the lecture, often gives these lectures. The lecture is recorded, and archived for future use by students and researchers, by uploading it to a file server (Lowe, 1999). There are several examples on the Internet where universities have made use of a full-length video recording of a lecture, e.g. CISAB at Indiana University http://www.indiana.edu/ animal/speakers/videolibrary.html or Lancaster University, http://humanresources.web.cern.ch/HumanResources/external/training/acad/acad0.asp or CERN http://agenda.cern.ch/displayLevel.php?fid $=72$

The opportunity to see an eminent speaker at another time is extremely useful for students, as not all student classes can be scheduled at the time of the lecture, and subsequent cohorts of students can also review the lecture, so are not disadvantaged.

One problem, because of the length of some lectures, is that the lecture recording is a large file size. Also the resulting video may be too long for students to usefully watch at one sitting, particularly as the visual cues and audience reaction may be missing. There may be long pauses, slow speech, and points where interaction with the audience takes place, which may not be appropriate for reviewing using the archived version, which could be removed if the original footage were to be edited.

\section{Video Conference of Live Lectures}

An alternative scenario is to invite a guest speaker to address our students, but use a videoconference system to enable the lecturer to present from their own place of work. The lecture may also be recorded for archiving purposes, but the speaker is live to our audience of students at the time of recording. This format has the advantage that the lecture is real time with the opportunity for interaction between the tutor and audience. One example is using videoconferencing with surgical 
students, where the availability of an expert in a particular specialism may be critical (Stain et al., 2005).

Real time lectures using a video conferencing link were tried between the author and a research partner. Each tutor gave a lecture on one of their specialist topics to a group of students at the other tutor's institution. MSN Messenger was used to deliver the videoconference lectures, and a combination of "talking head" video from the lecturer, presentation of PowerPoint slides and online resources were included. The lectures were interactive, though this did surprise some students, who were expecting to be passive listeners only. Overwhelmingly students enjoyed the events and could see the potential for enriching their learning experiences (Whatley, Zaitseva, \& Thissen, 2005).

Interaction is important in this type of lecture; the lecturer has the possibility to adapt the presentation to the audience response, such as interests shown, or need for further explanation. In this way the lecture could never be reproduced exactly, so the additional feature of recording the lecture for subsequent cohorts of students is useful. However, the adaptability of the lecture content will be lost with the recorded version, and the audience reaction may not be relevant to future cohorts (Mason, 1994).

\section{Video to Teach Skills}

If we believe that videos are a good means of helping students to learn skills, then recorded video, available on demand should prove to be useful to students. Short clips of video, up to 30 seconds, can often convey a lot of information, and when these are accompanied by textual information and short learning activities, can be a valuable learning tool. Nuggets is such a tool, which was developed to enable lecturers to build their own teaching material using video and associated text and learning activities (James, Laws, Staniland, Dowdle, \& Mollo, 2004). The resultant multimedia learning sessions are then embedded in Blackboard, for easy access to students. The Nuggets are designed for online learning, as part of a blended learning initiative, and specifically require students to engage in a small activity following from the video, to reinforce learning.

The choice of tool used to present the learning material depends upon the type of learning. For example a skill, which is traditionally taught by demonstrating in practice, lends itself admirably to presenting on video. The video could be an adjunct to face to face teaching, giving students an opportunity to revise the visual effect from the classroom. Other examples of using short video specifically for teaching a practical skill include cooking, folding napkins and tying knots (Painter 2000; Schwann \& Riempp, 2004).

\section{Technology Required}

Providing video on demand to students is currently recommended to support online or blended learning. Students can choose when and where to use the material, and can spend as long or as little time on each learning activity. Educational providers are considering provision of material via handheld devices, often called podcasting or webcasting, but the most common form of provision at present is using the Internet to distribute learning material (Zahn, Barquero, \& Schwan, 2004), which may in turn be viewed on a hand held device.

A difficulty with recorded video is the large file sizes of these products, occupying a lot of storage space on file servers or on a student's PC. Even with compression the file size of a recorded lecture can still be large, causing problems when downloading using a slow Internet connection. A real time lecture may also be problematic when connecting to the Internet from home.

Suitable technology to use for providing videos on demand is being developed. Streaming video is now widely used to transmit the video, particularly when the file size is large (Shephard, 2004). 
Downloading a video of more than 10 minutes would take a long time, before the user can watch it, so streaming is used, whereby the media can be watched or listened to whilst it is still being downloaded. A short length of the video is downloaded into a buffer on the users' computer, which is then displayed. Whilst it is being watched the next short piece is being downloaded into the buffer, and when this is watched, the first piece can be erased from the buffer. Video streaming is also useful for live lectures, because the video can be watched almost immediately, simulating real time.

Typically, an educational institution will store the videos on file servers, and users can connect to have them streamed to their PC whenever they want. It is also possible to use Internet sites, such as YouTube (available online at www.youtube.com), to host a video for students to use at any time.

A summary of the uses and features of different forms of video is given in Table 1. Each format has its potential in the learning agenda, for instance the interaction of an online lecture may be important in some cases, but the accessibility of an eminent speaker may be important in another case. A carefully planned summary video can help with understanding and remembering a topic, but is lacking interaction, other than controlling the playback of the video.

Table 1: Summary of features of video formats

\begin{tabular}{|l|c|c|c|c|c|}
\hline & $\begin{array}{l}\text { Helps with } \\
\text { understanding } \\
\text { of the topic }\end{array}$ & Interactive & $\begin{array}{l}\text { Helps with } \\
\text { remembering } \\
\text { the topic }\end{array}$ & $\begin{array}{l}\text { Study related } \\
\text { focus }\end{array}$ & $\begin{array}{l}\text { Improves mo- } \\
\text { tivation }\end{array}$ \\
\hline $\begin{array}{l}\text { Conference } \\
\text { video (1 hour) }\end{array}$ & $\mathrm{X}$ & $\mathrm{X}$ & & $\mathrm{X}$ & $\mathrm{X}$ \\
\hline $\begin{array}{l}\text { Recorded } \\
\text { module video } \\
\text { (50 mins) }\end{array}$ & $\mathrm{X}$ & $\mathrm{X}$ & $\mathrm{X}$ & $\mathrm{X}$ & \\
\hline $\begin{array}{l}\text { Online lecture } \\
(45 \text { mins) }\end{array}$ & $\mathrm{X}$ & $\mathrm{X}$ & $\mathrm{X}$ & $\mathrm{X}$ \\
\hline $\begin{array}{l}\text { Summary } \\
\text { video (5-10 } \\
\text { mins) }\end{array}$ & $\mathrm{X}$ & $\mathrm{X}$ & $\mathrm{X}$ & & \\
\hline $\begin{array}{l}\text { Demonstration } \\
\text { product (5- } \\
20 \text { mins) }\end{array}$ & & & & & $\mathrm{X}$ \\
\hline
\end{tabular}

\section{Preparing Summary Length Videos of Lectures}

Much research into using video is aimed at online provision for distance and open learning, where students are highly motivated to use the online resources, and accustomed to overcoming technical hitches (Ko \& Rossen, 2001). Campus based students, on the other hand, use the online resources to supplement their learning at the university, in particular preparation for assessed work, so provision should be appropriate for their needs of speedy delivery and relevance. Work on providing full length videos as well as shorter summaries linked to other communications tools has been presented by researchers at Lancaster University (Ramírez Martinell, Sime, \& O'Donoghue, 2006), who identified the difficulties of establishing the main points to include, in order to engage with constructivist learning principles.

Our research is based on the premise that students do not retain all that is said in a lecture the first time around. Providing PowerPoint slides to accompany a lecture, and enable students to annotate the lecture handouts, goes some way to helping them to learn from the lecture, but we are consid- 
ering whether providing summary lectures would help prepare students for assessment at the end of a module of study. As an additional resource we provided short summary video recordings of the weekly lectures, to supplement the PowerPoint lecture notes. Research by Reder and Anderson (1980) suggests that learning from a summary, where main points are highlighted, is better than from a full text.

Two methods were used to prepare the summary videos of lectures:

1. Recording a live lecture, and editing it down to highlights only later;

2. Recording a summary presentation of the lecture in the office.

No specialist equipment or software was needed for either of these methods. A hand held camcorder or a webcam was used, and MovieMaker, provided within MS Windows XP, was used for downloading the video from the camcorder, for editing down to the main summary points and for saving in a suitable format for uploading to the Internet. Text to accompany the video was added in a scrollable text box at the side of the video, based on the main points from the Powerpoint slides used in the original lecture. The procedure of recording and preparing a summary lecture video took about 1.5 hours, provided the lecturer had the required technical skills or a technical person to help.

The resulting short summary videos, about 5 to 10 minutes, were uploaded to a file sharing area on the Internet. After a few days the videos had been approved by YouTube and were ready to view. A link to the summary lecture videos was provided on the module pages in Blackboard and each week, for 6 weeks, a summary lecture was recorded, which covered the main areas of the syllabus.

The students involved were undergraduates, studying Multimedia Development, at level 2. There were 80 students taking this module, and about half of them did look at some or all of the summary lecture videos, either just after each had been published, or just before the examination as a revision aid.

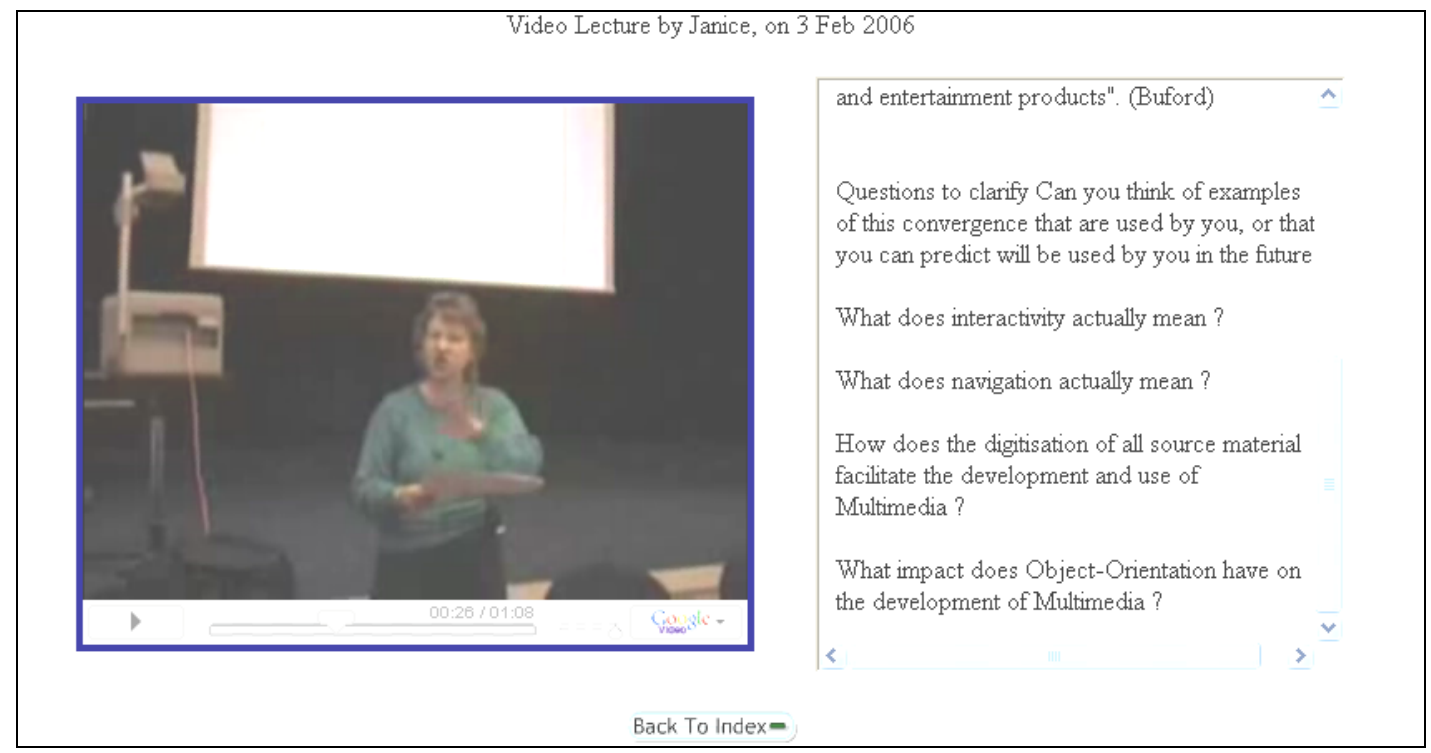

Figure 1: Playback of an edited recorded live lecture (first example).

The first attempts at providing summary lectures were recorded live in the lecture theatre, and edited later to reduce the size by only providing the main points from the lecture, Figures 1 and 2. 
The main findings from preparing these recordings is that the lighting in lecture theatres can be variable, the camera cannot always see the screen display as well as the lecturer and multiple cameras would be required to record the audience reaction to parts of the lecture. This is in contrast to findings of Fox, who worked on audio recordings of lectures and suggested that sound that was "good enough" could be used, as the content was the most important feature (Fox, 2006).

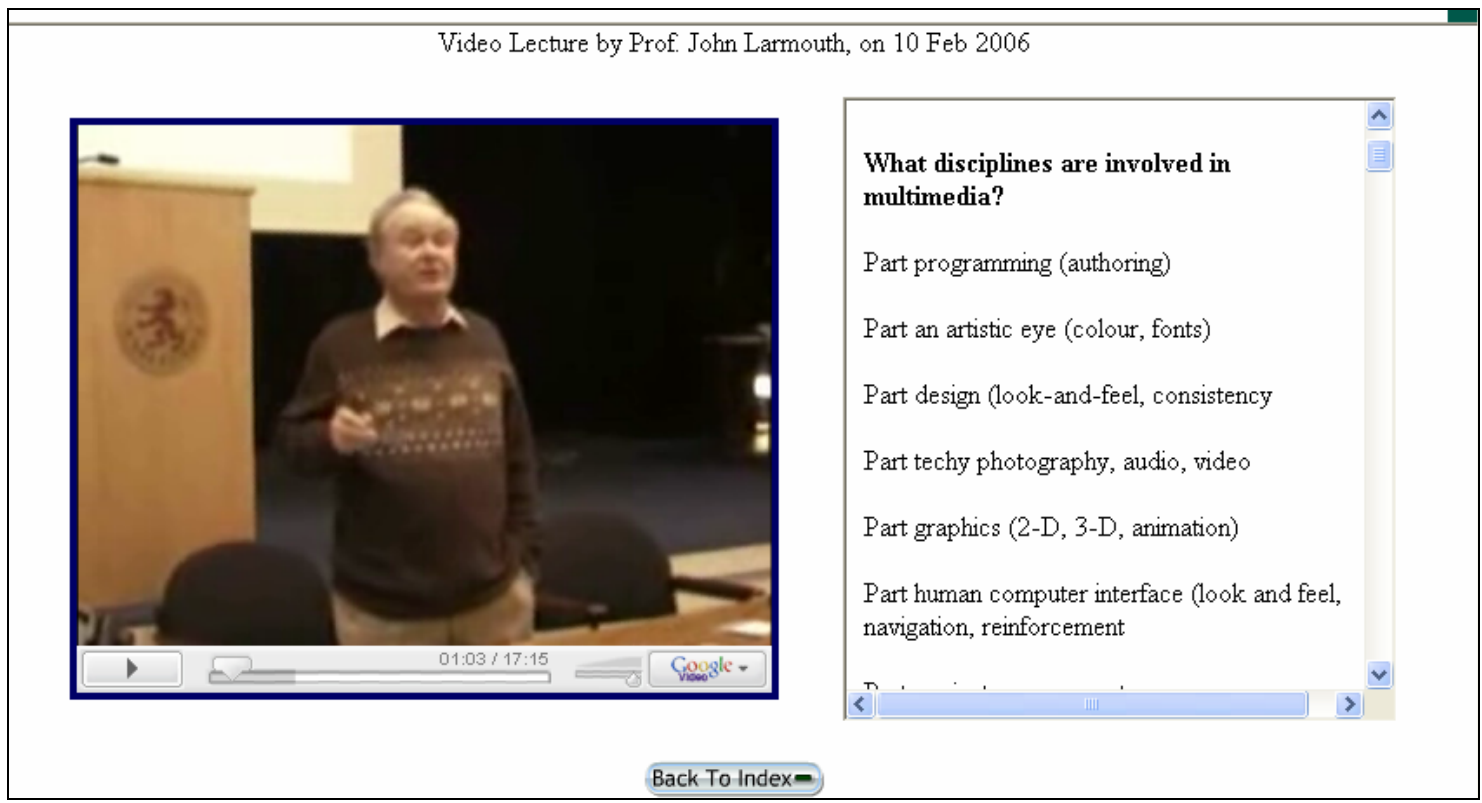

Figure 2: Playback of an edited recorded live lecture (second example).

As a result of these findings, the next few recordings were made elsewhere, either in the lecturer's office or an open area where the lighting was good, Figures 3 and 4 . The lecturer presented material from the lecture in a summary form, highlighting the structure of the lecture material and referring only to key points, giving some explanation when necessary.

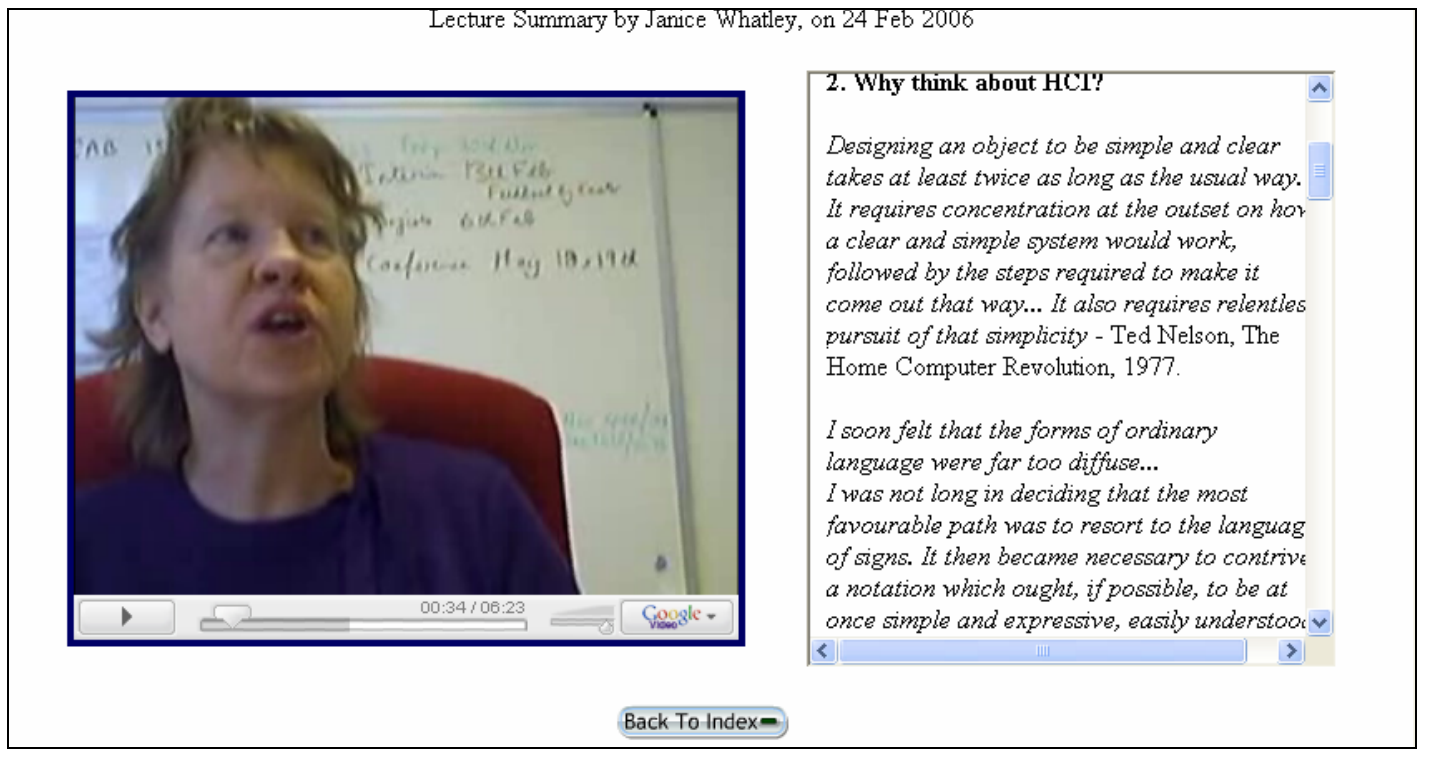

Figure 3: Lecture recorded in an office. 
The recording illustrated in Figure 3, shows that the lecturer needs to take care to look at the camera rather than the $\mathrm{PC}$ screen where the PowerPoint slides are being displayed. This was overcome in the example shown in Figure 4, by ensuring the PC display was at an appropriate position for the lecturer to see and control whilst talking to the camera. In all cases the choice of the text to include in the window beside the video was guided by the PowerPoint slides used in the original lecture, which the students already had access to.

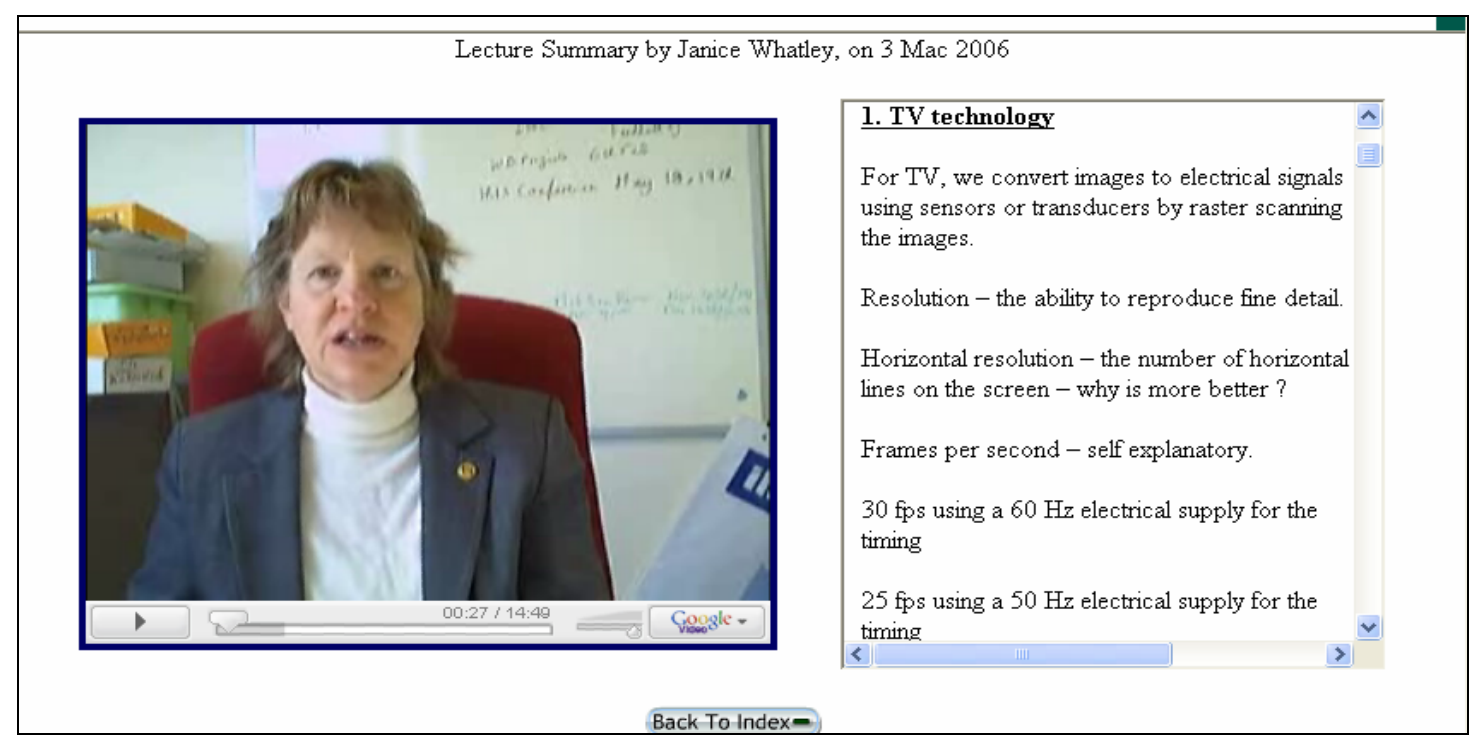

Figure 4: Lecture recorded in an office with improved eye contact with camera

\section{Research into Student Reactions to Summary Video Provision}

An interpretive approach was taken to this investigation, the emphasis being on discovery rather than checking, so meanings, perspectives and understanding within a natural setting, leading to examination of processes, was considered appropriate in order to interpret situations (Woods, Hammersley, \& Gomm, 1998). At the end of the teaching on the module, students were asked for their opinions and to describe how they used the summary lectures, and whether they regarded them as useful for helping to learn the topic or for their exam revision. These were gathered using informal interviews and questionnaires, after the assessment grading had been published, and analysed qualitatively to identify student reactions and inform our understanding of ways students may choose to use video in their learning. Not all of the students taking the module had viewed any of the summary lecture videos, much of the additional material provided on Blackboard is of a voluntary nature, and tutors have little control over students' use of this resource. The response rate to the questionnaire was very low, because students who did not view the summary lecture videos did not return them and of those who had, only half responded.

Initial analysis of the data suggests that providing these videos was very useful for students to use for their revision. They enjoyed watching the lectures again, to remind themselves of the main points covered. Some students, who missed the lecture the first time around, said that it was an excellent resource, providing more detail than in the handout of PowerPoint slides. 


\section{Discussion of Results}

Although there were minor variations in the ways we presented the summary lectures, they all had in common the provision of textual material to augment the video images, covering the main points mentioned in the video, similar to the content of the PowerPoint slides. According to Mayer text alongside the images is important for learning by the Contiguity Principle (Mayer, 2001), but not all students agreed with this, as "both can not be viewed at the same time". Providing text as well as images may be useful for accessibility, where users have some form of disability. The hard part is identifying appropriate text to include that truly augments the visual message.

The Multimedia Principle may be relevant, as students' learning for an examination is helped by these videos, as one student said: “...being both sound and video [the material] is more likely to sink in."

Some students agreed that the Signalling Principle may apply, "put things into perspective" and "provide an overview". From our feedback it was not possible to justify the Modality Principle, which may be more appropriate for training videos, or the Personalization Principle, because a summary lecture is unlikely to have a conversational style.

When asked whether the summary lecture videos helped with their revision for the examination, there was a clear consensus that they did, "extremely useful!!!" was one response, "it helped me to study the whole module in one third of the time...I learn better from hearing people instead of reading".

One difficulty is in deciding what main points the lecture can be broken down into, and how much detail is required for understanding of these main points, as an aid to revision for students. A lot will depend upon the prior understanding the students have, their learning style and motivation to prepare in advance for an assessment. As one student said "it promotes a different mode of learning for different learning styles". There is a danger of emphasising points that will occur in the assessment, to the detriment of a more complete coverage of the topic, which would aid a deeper learning approach.

Young \& Asensio suggest a 3I Framework: Image, Interactivity and Integration, (Young \& Asensio, 2003).

This identifies the need for students to be able to interact with the images, and the importance of video being distributed so that it is accessible to all students, using any technology. The ability to start and stop the video and control the presentation is desirable, and reading the reinforcing text makes for good interactivity, though it is difficult to determine the extent of students' involvement with the material. The video we provided certainly allowed students access, choice and control over their learning (Young \& Asensio, 2003). Face to face lectures on campus are often regarded by students as passive experiences, which do not require interaction, so the online provision could be regarded as no worse (Mason, 1994).

When using original footage of a live lecture, much of the interactivity in the form of student questions and answers had to be cut out, because sound or lighting was not good enough to pick up the questions from the audience. A second camera angle to capture images of students who ask questions could be used, but permission to include those clips in the final product would have to be gained. The summary lecture videos presented on Blackboard could be augmented by a discussion forum or chat session to enable some form of interaction with the tutor to elaborate on issues that might arise from the material presented in the video.

On a practical note we found that eye contact when recording the video is to be encouraged, by ensuring the lecturer looks into the camera most of the time. The lectures recorded in the office were superior to those recorded in the lecture theatre, for a number of reasons: the material could 
be rehearsed, so the flow of the lecture was slicker; sound and lighting levels were more controllable; there was less extraneous noise; unnecessary movement was avoided; and the quality of the completed video was better.

\section{Conclusions}

Feedback from the students indicated that they felt the summary videos we produced were useful for their revision of material in preparation for the examination. They also found them useful on occasions when they had missed a lecture, needed some help to understand a topic or to help put the material into perspective. Providing text alongside the video may be useful for some students in supplying a structure to the lecture content.

Summary lecture videos may be useful for reinforcing learning as the module progresses, or for revision of the material in preparation for an examination, and the content and arrangement may need to be adapted for each case. More research into the content of summary videos is to be carried out to establish the best arrangement.

What is important is that the quality of the recording should be as good as possible, using better equipment than we used, with good lighting and sound recording. The technology should be robust so that breaks in transmission do not occur, and streaming is recommended for summary videos.

As educators, we are looking for the best means to help students in their learning. We believe there are improved means of helping through the use of learning technology advancements, which are becoming less costly everyday. Taking advantage of developments in technology, combined with appropriate learning theory supports the suggestion that students should be exposed repeatedly to the topic through different delivery methods in order for them to 'digest' the subject matter. Therefore, the summary videos (besides classroom lecture, MS PowerPoint-slides note, handouts and tutorials) are another practical and technically possible means of achieving this. The preliminary findings from this study show some significant results that encourage the merit of further study into the use of summary videos.

\section{References}

Bligh, D. (1974). What's the use of lectures? London: Penguin.

Fox, R. (2006). Audio lectures in finance: Use, value and development cost. Innovative Learning in Action, $5,18-23$.

Goodyear, P., \& Steeples, C. (1998). Creating shareable representations of practice. Association for Learning Technology Journal, 6(3), 16-23.

Issroff, K. \& Scanlon, E. (2002). Using technology in higher education: An activity theory perspective. Journal of Computer Assisted Learning, 18, 77-83.

James, M., Laws, E., Staniland, K., Dowdle, D., \& Mollo, B., (2004). Nuggets: Encouraging academic colleagues to become independent in their development of media-enriched and interactive online content. Proceedings: Education in a Changing Environment, University of Salford, UK.

Ko, S. \& Rossen, S. (2001). Teaching online: A practical guide. New York: Houghton Mifflin.

Lisewski, B. (2004). Implementing a learning technology strategy: Top-down strategy meets bottom-up culture. Association for Learning Technology, 12(2), 173-186.

Lowe, D. (1999). Web-based access to audio and video learning materials. AusWeb99 Australian World Wide Web Conference, Lismore, NSW, Australia.

Mason, R. (1994). Using communications media in open and flexible learning. London: Kogan Page. 
Mayer, R. (2001). Multimedia learning. Cambridge: Cambridge University Press.

Mayer, R. \& Anderson, R. (1991). Animations need narrations: An experimental test of a dual coding hypothesis. Journal of Educational Psychology, 83(4), 484-490.

Painter, J. (2000). Teaching garnishing and napkin folding to hospitality students: Comparing the effectiveness of written diagrams versus multi-media computer videos (a pilot study). Foodservice Research International, 12(3), 175.

Phelps, J. \& Tidmarsh, A. (2005). Extending digital video for learning and teaching. ALT-C, Manchester.

Ramírez Martinell, A., Sime, J.-A., \& O’Donoghue, M. (2006). Design of a constructivist virtual learning environment composed by video summaries. Edutec 2006. Education in Virtual Environments: Quality and Effectiveness in E-learning. Rovira I Virgili Universiyt, Tarragona, Spain.

Reder, L. M. \& Anderson, J. R. (1980). A comparison of texts and their summaries: Memorial consequences. Journal of Verbal Learning and Verbal Behavior, 19, 121-134.

Schwann, S. \& Riempp, R. (2004). The cognitive benefits of interactive videos: Learning to tie nautical knots. Learning and Instruction, 14, 293-305.

Severin, W. (1967). Another look at cue summation. Audio Visual Communications Review, 15, 233-245.

Shephard, K. (2004). Streaming audio and video for course design. Southampton: University of Southampton.

Shepard, R. N., \& Cooper. L. A. (1982). Mental images and their transformations. Cambridge, MA: MIT Press.

Sorden, S. (2005). A cognitive approach to instructional design for multimedia learning. Informing Science Journal, 8, 263-279. Available at http://inform.nu/Articles/Vol8/v8p263-279Sorden34.pdf

Stain, S., Mitchell, M., Belue, R., Mosley, V., Wherry, S., Adams, C.Z., et al. (2005). Objective assessment of videoconferenced lectures in a surgical clerkship. The American Journal of Surgery, 189, 81-84.

Vogel, M. \& Oliver, M. (2006). Learning design tools project: Designing for learning in virtual learning environments. London, CETL, Goldsmiths: 55.

Whatley, J., Zaitseva, E., \& Thissen, F., (2005). CAB project, Stage 7 report: Using video in international collaboration. Salford, University of Salford.

Woods, P., Hammersley, M., \& Gomm, R., (1998). Educational research methods. Milton Keynes, Open University.

Young, C. \& Asensio, M. (2002). Looking through three "I"s: The pedagogic use of streaming video. Third International Conference of Networked Learning, Sheffield, March 2002

Zahn, C., Barquero, B. \& Schwan, S. (2004). Learning with hyperlinked videos - Design criteria and efficient strategies for using audiovisual hypermedia. Learning and Instruction, 14, 275-291. 


\section{Biographies}

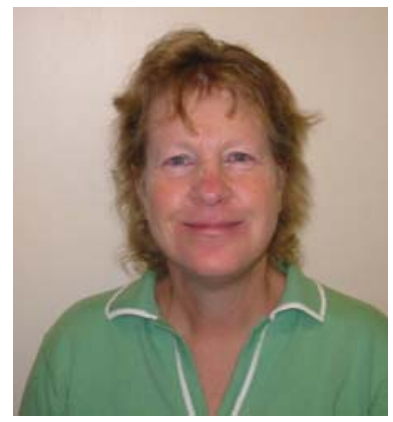

Janice Whatley has lectured in computing and information systems for eight years, using various forms of computer mediated communication to support learners. At present she is a lecturer in the Salford Business School, University of Salford (UK), where ongoing research includes the different ways in which communication tools may be used to support collaboration in online learning, agent technology to support student team working, and innovative uses of multimedia in learning.

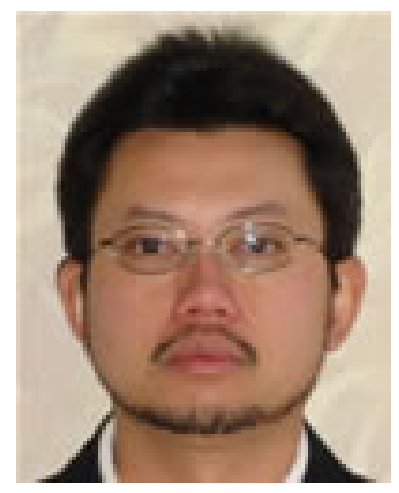

Amrey Ahmad is a postgraduate research student at the Salford Business School - Information Systems Group. His research studies focus on the use of Asynchronous CMC within the Virtual Learning Environment. He has BSc. and MSc. degrees in the Information Technology discipline, also experience in an e-learning system project implementation at two Malaysian universities. 